\title{
Factors Affecting the Turnover Intention of Dental Hygienists: Emotional Labor, Job Satisfaction, and Social Support
}

\author{
Sun-Mi Noh*, Hee-Jung Lim*, Myoung-Hee Kim, Ae-Jung Im, and Do-Seon Lim ${ }^{\dagger}$ \\ Department of Dental Hygiene, Graduate School of Public Health Science, Eulji University, Seongnam 13135, Korea
}

This study aims to contribute to managing the human resource of dental hygienists and qualitatively enhancing dental medical services by examining factors that affect their turnover intention. Therefore, it attempted to examine their degrees of emotional labor, job satisfaction, and social support and the effects of each variable on turnover intention. This study administered self-reporting questionnaires to dental hygienists working in dental hospitals, dental clinics, and general or university hospitals in Seoul Metropolis and Gyeonggi-do by conducting convenience sampling, from May 18, 2017 to August 4, 2017. Among a total of 224 copies that were distributed, a total of 223 copies, excluding 1 copy with poor responses, were used in the data analysis. The research tools comprised 12 questions on general characteristics, 24 questions on emotional labor (4-point Likert scale), 16 questions on job satisfaction (5-point Likert scale), 8 questions on social support (4-point Likert scale), and 4 questions on turnover (5-point Likert scale). The scores of dental hygienists were as follows: emotional labor, 2.49 out of 4; job satisfaction, 3.14 out of 5; social support, 3.04 out of 4; and turnover intention, 3.07 out of 5 . Their turnover intention has a positive correlation with emotional labor, but a negative correlation with job satisfaction and social support. It was found that some factors that significantly influence turnover intention included the amount of overtime work and job satisfaction. Thus, dental medical institutes should search for measures, including improvement of the working environment, to reduce the amount of overtime work and enhance job satisfaction.

Key Words: Dental hygienists, Emotional labor, Job satisfaction, Social support, Turnover intention

\section{Introduction}

Recently, as life expectancy is extended with rapid advances in medical technologies, awareness of oral health has grown, the demand for oral care has increased, and a variety of government oral health policies have changed ${ }^{1)}$. In addition, as dental care institutions become larger, more specialized, and specified, they have expanded the work scope of dental hygienists and provided a work environment that could increase their physical and mental stress ${ }^{2}$. In such a work environment, dental hygienists are highly likely to be exposed to emotional labor, which refers to a conflict between the emotions required by the organization and the actual emotions that an individual experiences ${ }^{3)}$.
Korea Employment Information Service recently reported that dental hygienists rank 14th among other emotional labor occupations and are categorized as a group with a high level of emotional labor ${ }^{4}$. Studies found that when emotional labor was repeated or continued, not only did it harm physical and mental health, but it also increased negligence, malpractice, lower job satisfaction, and turnover $^{5,6}$. In 2010, the Korean Health and Medical Workers' Union reported that the average number of dental hygienists' years of clinical practice was $5.7^{7}$, and more than $60 \%$ of dental hygienists with 6 to 10 years of clinical practice, who should play a central role in dental care services, experienced turnover ${ }^{8}$. Not only does this consume time and cost for dental care institutions, which

*These authors contributed equally to this work. 
must collaborate to recruit and train new dental hygienists due to repeated turnover, but it can also undermine the quality of dental care services due to a lack of experienced dental hygienists ${ }^{9}$.

Job satisfaction is one of the most important variables related to turnover intention, and it was reported that job satisfaction is affected by satisfaction with one's job itself, depending on personal attitudes, values, beliefs, and needs, and other very complex factors such as wages, employee benefits, working hours, and relationships with colleagues $^{10)}$. Kim et al. ${ }^{11)}$ revealed that a higher level of job satisfaction increased organizational commitment, lowered the behavior of searching for other workplaces and turnover intention, and reduced the turnover rate. Yoon et al. ${ }^{12)}$ reported that a lower level of job satisfaction increased turnover intention, while a better interactive relationship with one's group lowered turnover intention.

In addition, social support is a positive resource that an individual can gain from an interpersonal relationship, and has been reported to contribute to increasing job satisfaction and decreasing turnover intention ${ }^{13)}$. Kim et al. ${ }^{14)}$ reported that clinical nurses with a higher level of social support perceived a lower level of emotional labor, and their job satisfaction increased ${ }^{15)}$. As such, social support has long been reported as a buffer to alleviate a negative psychological state ${ }^{13)}$, and presented as another variable related to turnover intention. To date, previous studies on dental hygienists' turnover intention have been performed actively in relation to job satisfaction ${ }^{12,16)}$, job stress ${ }^{16,17)}$, emotional burnout ${ }^{3,17)}$, organizational communication satisfaction $^{18)}$, organizational commitment ${ }^{19)}$, intramural marketing $^{20)}$, psychological empowerment ${ }^{21)}$, verbal abuse and emotional reaction ${ }^{22)}$, the Myers-Briggs Type Indicator (MBTI) and Enneagram ${ }^{23)}$, and emotional labor ${ }^{5,8)}$. The findings of these studies demonstrate that turnover intention is affected by many different variables, and in this respect, it is necessary to approach turnover intention not as a single factor but in a more comprehensive and multi-faceted way.

This study aims to identify the level of dental hygienists' emotional labor, job satisfaction, social support, and turnover intention, and the extent to which each variable contributes to turnover intention. By so doing, this study intends to provide a basic reference to help operate the human resources management of dental hygienists and improve the quality of dental care services.

\section{Materials and Methods}

\section{Subjects}

This study explained its purposes to 224 dental hygienists working in dental hospitals, dental clinics, and general or university hospitals located in Seoul and Gyeonggi-do, from May 18, 2017 to August 4, 2017 and administered a self-administered questionnaire on those who provided voluntary consent. The sample size was calculated using the $G^{*}$ Power 3.1 software program, and in a hierarchical multiple regression analysis, this study satisfied the minimum of 204 subjects required to maintain a statistical significance of 0.05 , an effect size of 0.15 , and a statistical power of 0.95 . A total of 223 copies were used in the final analysis, excluding 1 of the retrieved 224 copies, which had incomplete responses. Ethical approval for this study was provided by Eulji University's Institutional Review Board (IRB approval no. EU17-22).

\section{Tools}

The questionnaire used in this study gathered information on general characteristics, emotional labor, job satisfaction, social support, and turnover intention. The general characteristics comprised age (29 or younger, 30 34, 35 39, 40 or older), marital status (married, unmarried, other), education level (college graduation, university graduation, postgraduate course, or graduation), working area (Seoul, Gyeonggi-do), working place (dental clinic, dental hospital, general or university hospital), employment status (regular, contract, part-time), total career (less than 1 year, $1 \sim 3$ years, $3 \sim 5$ years, $5 \sim 10$ years, 10 years or more), duty responsibility (staff, team leader, chief), work position (none, coordinated collaboration throughout dental treatment, preventive treatment and education, reception and counseling), frequency of overtime work (none, $1 \sim 2$ times, $3 \sim 4$ times, 5 times or more per week), working days (5 days, 6 days, 5 days [including night work], other), and monthly income (Korean won [KRW] 1.5 million or less, KRW $1.5 \sim 2$ million, KRW $2 \sim$ 2.5 million, KRW 2.5 3 million, KRW 3 million or 
more). To examine the level and intensity of the subjects' emotional labor, this study used 24 questions from the Korean emotional labor measurement tool developed by Chang et al. ${ }^{24)}$, while 8 questions developed by Park ${ }^{13)}$ and adapted by Jeung ${ }^{25)}$ were used for social support. A 4-point scale ranging from "strongly disagree (1 point)" to "strongly agree (4 points)" was used for questions on emotional labor and social support, and 7 questions from the emotional labor tool were converted into the scale. To investigate job satisfaction, this study used 16 questions adapted by $\mathrm{Rye}^{26)}$ from the Index of Work Satisfaction developed by Slavitt et al. ${ }^{27)}$, and 4 questions adapted by Yoon and $\mathrm{Kim}^{28)}$ from those developed by Lawler (1983) were used for turnover intention. These questions on job satisfaction and turnover intention used the 5-point scale of "strongly disagree (1 point)" to "strongly agree (5 points)." When it came to the questionnaire's reliability, emotional labor showed a Cronbach's $\alpha$ of 0.829 , job satisfaction a Cronbach's $\alpha$ of 0.910 , social support a Cronbach's $\alpha$ of 0.859 , and turnover intention a Cronbach's $\alpha$ of 0.917 .

\section{Analytical methods}

The collected data were analyzed using IBM SPSS Statistics 22.0 (IBM Co., Armonk, NY, USA), and the p-value was set at less than 0.05 to verify statistical significance. Means and standard deviations were examined based on the median score of 2 for emotional labor and social support, which used the 4-point scale, and that of 2.5 for job satisfaction and turnover intention, which used the 5-point scale. This study performed a t-test and an ANOVA to identify differences in emotional labor, job satisfaction, social support, and turnover intention by the subjects' general characteristics, and Duncan's post hoc test to examine differences between groups. Pearson's correlation coefficient was used to examine correlations between emotional labor, job satisfaction, social support, and turnover intention. A hierarchical multiple regression analysis was performed to investigate the factors that contributed to turnover intention.

\section{Results}

1. Score distribution of emotional labor, job satisfaction, social support, and turnover intention

The subjects scored 2.49 and 3.04 out of 4 points in emotional labor and social support, respectively; they scored 3.14 and 3.07 out of 5 points in job satisfaction and turnover intention, respectively (Table 1 ).

2. Emotional labor, job satisfaction, social support, and turnover intention by general characteristics

Emotional labor was high in those aged 40 or older, those who were married, those with 10 years or more of total career experience, and those with a monthly income of KRW 3 million $(\mathrm{p}<0.01)$. There was no significant difference for job satisfaction across most questionnaire items. Social support was high in those aged 29 or less, those who were unmarried, those with 3 to 5 years of total career experience, and those with a monthly income of KRW 1.5 to 2 million $(\mathrm{p}<0.05)$. In terms of education level, most respondents were university graduates, while dental hospitals were the most common working place $(\mathrm{p}<$ 0.05). In terms of working place, general or university hospitals showed the highest turnover intention with 3.24 points; for total career, those with 5 to 10 years of total career experience scored the highest in turnover intention with 3.23 , but there was no significant difference (Table 2).

3. Emotional labor, job satisfaction, social support, and turnover intention by occupational characteristics

For emotional labor, the group engaged in reception and counseling showed a high score with 2.64; for job satisfaction, the group with no overtime work showed a high score with 3.21. For social support, the group

Table 1. Emotional Labor, Job Satisfaction, Social Support, and Turnover Intention

\begin{tabular}{lcc}
\hline Characteristic & Likert scale & Value \\
\hline Emotional labor & 4 & $2.49 \pm 0.76$ \\
Job satisfaction & 5 & $3.14 \pm 0.94$ \\
Social support & 4 & $3.04 \pm 0.61$ \\
Turnover intention & 5 & $3.07 \pm 1.16$ \\
\hline
\end{tabular}

Values are presented as mean \pm standard deviation. 
Table 2. Emotional Labor, Job Satisfaction, Social Support, and Turnover Intention by General Characteristics $(n=223)$

\begin{tabular}{|c|c|c|c|c|c|}
\hline & $\mathrm{n}(\%)$ & Emotional labor & Job satisfaction & Social support & Turnover intention \\
\hline \multicolumn{6}{|l|}{ Age (yr) } \\
\hline$\leq 29$ & $124(55.6)$ & $2.44 \pm 0.33^{\mathrm{a}}$ & $3.14 \pm 0.60$ & $3.14 \pm 0.46^{\mathrm{b}}$ & $3.10 \pm 1.05$ \\
\hline $30 \sim 34$ & $46(20.6)$ & $2.56 \pm 0.35^{\mathrm{ab}}$ & $3.05 \pm 0.60$ & $2.96 \pm 0.37^{\mathrm{ab}}$ & $3.22 \pm 0.90$ \\
\hline $35 \sim 39$ & $30(13.5)$ & $2.61 \pm 0.29^{\mathrm{b}}$ & $3.23 \pm 0.59$ & $2.85 \pm 0.31^{\mathrm{a}}$ & $2.82 \pm 0.92$ \\
\hline$\geq 40$ & $23(10.3)$ & $2.65 \pm 0.36^{\mathrm{b}}$ & $3.16 \pm 0.79$ & $2.93 \pm 0.45^{\mathrm{a}}$ & $2.91 \pm 1.30$ \\
\hline p-value & & 0.004 & 0.640 & 0.001 & 0.336 \\
\hline \multicolumn{6}{|l|}{ Marriage } \\
\hline Unmarried & $159(71.3)$ & $2.47 \pm 0.34$ & $3.12 \pm 0.61$ & $3.10 \pm 0.45$ & $3.13 \pm 1.02$ \\
\hline Married & $64(28.7)$ & $2.61 \pm 0.32$ & $3.18 \pm 0.65$ & $2.90 \pm 0.34$ & $2.91 \pm 1.06$ \\
\hline p-value & & 0.006 & 0.487 & 0.001 & 0.155 \\
\hline \multicolumn{6}{|l|}{ Education level } \\
\hline College & $125(56.1)$ & $2.55 \pm 0.32$ & $3.09 \pm 0.60$ & $2.97 \pm 0.41^{\mathrm{a}}$ & $3.11 \pm 1.01$ \\
\hline University & $77(34.5)$ & $2.46 \pm 0.36$ & $3.17 \pm 0.63$ & $3.16 \pm 0.44^{\mathrm{b}}$ & $3.09 \pm 1.07$ \\
\hline Postgraduate course or graduation & $21(9.4)$ & $2.46 \pm 0.38$ & $3.27 \pm 0.67$ & $3.04 \pm 0.46^{\mathrm{ab}}$ & $2.79 \pm 1.07$ \\
\hline p-value & & 0.138 & 0.411 & 0.006 & 0.417 \\
\hline \multicolumn{6}{|l|}{ Working area } \\
\hline Seoul & $115(51.6)$ & $2.53 \pm 0.34$ & $3.15 \pm 0.66$ & $3.02 \pm 0.46$ & $2.98 \pm 1.03$ \\
\hline Gyeonggi-do & $108(48.4)$ & $2.49 \pm 0.34$ & $3.13 \pm 0.57$ & $3.06 \pm 0.41$ & $3.16 \pm 1.03$ \\
\hline p-value & & 0.407 & 0.831 & 0.497 & 0.208 \\
\hline \multicolumn{6}{|l|}{ Working place } \\
\hline Dental clinic & $138(61.9)$ & $2.49 \pm 0.35$ & $3.19 \pm 0.64$ & $3.04 \pm 0.43^{\mathrm{b}}$ & $3.05 \pm 1.05$ \\
\hline Dental hospital & $61(27.4)$ & $2.50 \pm 0.33$ & $3.07 \pm 0.57$ & $3.15 \pm 0.42^{\mathrm{b}}$ & $3.05 \pm 0.98$ \\
\hline General or university hospital & $24(10.8)$ & $2.63 \pm 0.32$ & $3.03 \pm 0.64$ & $2.79 \pm 0.41^{\mathrm{a}}$ & $3.24 \pm 1.14$ \\
\hline p-value & & 0.160 & 0.322 & 0.002 & 0.698 \\
\hline \multicolumn{6}{|l|}{ Employment status } \\
\hline Regular & $177(79.4)$ & $2.51 \pm 0.33$ & $3.16 \pm 0.59$ & $3.05 \pm 0.44$ & $3.10 \pm 1.03$ \\
\hline Contract & $31(13.9)$ & $2.51 \pm 0.39$ & $3.09 \pm 0.77$ & $3.06 \pm 0.43$ & $2.85 \pm 1.08$ \\
\hline Part-time & $15(6.7)$ & $2.54 \pm 0.33$ & $3.00 \pm 0.60$ & $2.87 \pm 0.33$ & $3.17 \pm 0.98$ \\
\hline p-value & & 0.940 & 0.603 & 0.273 & 0.424 \\
\hline \multicolumn{6}{|l|}{ Total career (y) } \\
\hline$<1$ & $36(16.1)$ & $2.34 \pm 0.35^{\mathrm{a}}$ & $3.13 \pm 0.61$ & $3.14 \pm 0.54^{\mathrm{b}}$ & $3.02 \pm 0.96$ \\
\hline $1 \sim 3$ & $35(15.7)$ & $2.43 \pm 0.33^{\mathrm{a}}$ & $3.16 \pm 0.60$ & $3.14 \pm 0.40^{\mathrm{b}}$ & $3.19 \pm 1.18$ \\
\hline $3 \sim 5$ & $36(16.1)$ & $2.44 \pm 0.24^{\mathrm{a}}$ & $3.17 \pm 0.53$ & $3.16 \pm 0.39^{\mathrm{b}}$ & $3.08 \pm 0.96$ \\
\hline $5 \sim 10$ & $55(24.7)$ & $2.59 \pm 0.35^{\mathrm{b}}$ & $3.09 \pm 0.65$ & $3.03 \pm 0.43^{\mathrm{ab}}$ & $3.23 \pm 0.95$ \\
\hline$\geq 10$ & $61(27.4)$ & $2.62 \pm 0.33^{\mathrm{b}}$ & $3.16 \pm 0.67$ & $2.87 \pm 0.36^{\mathrm{a}}$ & $2.88 \pm 1.11$ \\
\hline p-value & & $<0.001$ & 0.963 & 0.003 & 0.410 \\
\hline \multicolumn{6}{|l|}{ Monthly income (million won) } \\
\hline$<150$ & $23(10.3)$ & $2.42 \pm 0.31^{\mathrm{a}}$ & $3.07 \pm 0.55$ & $2.91 \pm 0.30^{\mathrm{a}}$ & $2.90 \pm 0.78$ \\
\hline $150 \sim 200$ & $76(34.1)$ & $2.38 \pm 0.35^{\mathrm{a}}$ & $3.11 \pm 0.63$ & $3.17 \pm 0.47^{b}$ & $3.22 \pm 1.03$ \\
\hline $200 \sim 250$ & $64(28.7)$ & $2.58 \pm 0.29^{\mathrm{b}}$ & $3.12 \pm 0.60$ & $3.07 \pm 0.42^{\mathrm{ab}}$ & $3.06 \pm 1.05$ \\
\hline $250 \sim 300$ & $38(17.0)$ & $2.61 \pm 0.36^{\mathrm{b}}$ & $3.11 \pm 0.66$ & $2.92 \pm 0.41^{\mathrm{a}}$ & $3.07 \pm 1.17$ \\
\hline$\geq 300$ & $22(9.9)$ & $2.68 \pm 0.31^{\mathrm{b}}$ & $3.42 \pm 0.59$ & $2.86 \pm 0.36^{\mathrm{a}}$ & $2.77 \pm 1.00$ \\
\hline p-value & & $<0.001$ & 0.258 & 0.003 & 0.414 \\
\hline
\end{tabular}

Values are presented as $\mathrm{n}(\%)$ or mean \pm standard deviation.

Likert scale: emotional labor, 4; job satisfaction, 5; social support, 4; turnover intention, 5.

p-value was calculated by t-test or one-way ANOVA.

${ }^{\mathrm{a}, \mathrm{b}}$ Post hoc test was conducted from Duncan test. Different letters denote significant differences between groups.

engaged in patient preventative treatment and education scored high with 3.18; for turnover intention, the group working overtime 5 times or more per week scored the highest with $3.56(\mathrm{p}<0.05$; Table 3$)$. 
Table 3. Emotional Labor, Job Satisfaction, Social Support, and Turnover Intention by Job Characteristics $(n=223)$

\begin{tabular}{|c|c|c|c|c|c|}
\hline & $\mathrm{n}(\%)$ & Emotional labor & Job satisfaction & Social support & Turnover intention \\
\hline \multicolumn{6}{|l|}{ Duty responsibility } \\
\hline Staff & $165(74.0)$ & $2.48 \pm 0.33$ & $3.08 \pm 0.57$ & $3.06 \pm 0.44$ & $3.17 \pm 0.98$ \\
\hline Team leader & $31(13.9)$ & $2.59 \pm 0.34$ & $3.22 \pm 0.69$ & $2.96 \pm 0.35$ & $2.85 \pm 0.96$ \\
\hline Chief & $27(12.1)$ & $2.59 \pm 0.38$ & $3.37 \pm 0.75$ & $2.99 \pm 0.47$ & $2.73 \pm 1.36$ \\
\hline p-value & & 0.109 & 0.056 & 0.389 & 0.055 \\
\hline \multicolumn{6}{|l|}{ Work position } \\
\hline None & $66(29.6)$ & $2.54 \pm 0.36^{\mathrm{ab}}$ & $3.18 \pm 0.68$ & $2.97 \pm 0.47^{\mathrm{ab}}$ & $2.89 \pm 1.09$ \\
\hline $\begin{array}{l}\text { Coordinated collaboration } \\
\text { throughout dental treatment }\end{array}$ & $106(47.5)$ & $2.45 \pm 0.33^{\mathrm{a}}$ & $3.11 \pm 0.58$ & $3.13 \pm 0.41^{\mathrm{b}}$ & $3.18 \pm 1.00$ \\
\hline $\begin{array}{l}\text { Preventive treatment and } \\
\text { education }\end{array}$ & $13(5.8)$ & $2.46 \pm 0.33^{\mathrm{a}}$ & $3.38 \pm 0.46$ & $3.18 \pm 0.44^{\mathrm{b}}$ & $2.98 \pm 1.14$ \\
\hline Reception and counseling work & $38(17.0)$ & $2.64 \pm 0.33^{\mathrm{b}}$ & $3.08 \pm 0.65$ & $2.86 \pm 0.37^{\mathrm{a}}$ & $3.09 \pm 0.98$ \\
\hline p-value & & 0.023 & 0.426 & 0.002 & 0.337 \\
\hline \multicolumn{6}{|l|}{ Overtime work (count/wk) } \\
\hline None & $86(38.6)$ & $2.47 \pm 0.31$ & $3.21 \pm 0.59^{\mathrm{b}}$ & $3.09 \pm 0.44$ & $2.88 \pm 1.05^{\mathrm{a}}$ \\
\hline $1 \sim 2$ & $96(43.0)$ & $2.52 \pm 0.34$ & $3.17 \pm 0.56^{\mathrm{b}}$ & $3.02 \pm 0.44$ & $3.04 \pm 0.96^{\mathrm{a}}$ \\
\hline $3 \sim 4$ & $24(10.8)$ & $2.58 \pm 0.36$ & $2.83 \pm 0.66^{\mathrm{a}}$ & $2.92 \pm 0.41$ & $3.53 \pm 1.07^{\mathrm{a}}$ \\
\hline$\geq 5$ & $17(7.6)$ & $2.54 \pm 0.46$ & $2.99 \pm .85^{\mathrm{a}}$ & $3.10 \pm 0.42$ & $3.56 \pm 1.06^{\mathrm{a}}$ \\
\hline p-value & & 0.543 & 0.039 & 0.308 & 0.008 \\
\hline \multicolumn{6}{|l|}{ Working day per week } \\
\hline 5 & $99(44.4)$ & $2.55 \pm 0.32$ & $3.13 \pm 0.60$ & $3.04 \pm 0.45$ & $3.04 \pm 1.06$ \\
\hline 6 & $58(26.0)$ & $2.51 \pm 0.32$ & $3.08 \pm 0.71$ & $3.02 \pm 0.46$ & $3.15 \pm 1.07$ \\
\hline 5 (night work) & $52(23.3)$ & $2.47 \pm 0.40$ & $3.25 \pm 0.56$ & $3.08 \pm 0.37$ & $3.00 \pm 0.99$ \\
\hline Others & $14(6.3)$ & $2.38 \pm 0.35$ & $3.05 \pm 0.58$ & $3.01 \pm 0.49$ & $3.20 \pm 0.99$ \\
\hline p-value & & 0.285 & 0.466 & 0.850 & 0.848 \\
\hline
\end{tabular}

Values are presented as $\mathrm{n}(\%)$ or mean \pm standard deviation.

Likert scale: emotional labor, 4; job satisfaction, 5; social support, 4; turnover intention, 5.

p-value was calculated by t-test or one-way ANOVA.

${ }^{\mathrm{a}, \mathrm{b}}$ Post hoc test was conducted from Duncan test. Different letters denote significant differences between groups.

Table 4. Correlation between Emotional Labor, Job Satisfaction, Social Support, and Turnover Intention

\begin{tabular}{lcccc}
\hline & $\begin{array}{c}\text { Emotional } \\
\text { labor }\end{array}$ & $\begin{array}{c}\text { Job } \\
\text { satisfaction }\end{array}$ & $\begin{array}{c}\text { Social } \\
\text { support }\end{array}$ & $\begin{array}{c}\text { Turnover } \\
\text { intention }\end{array}$ \\
\hline Emotional labor & 1 & & & \\
Job satisfaction & $-0.383^{*}$ & 1 & & \\
Social support & $-0.312^{*}$ & $0.479 *$ & 1 & \\
Turnover intention & $0.282^{*}$ & $-0.704 *$ & $-0.362 *$ & 1 \\
\hline
\end{tabular}

p-value was calculated by Spearman correlation coefficient. ${ }^{*} \mathrm{p}<0.01$.

\section{Correlations between emotional labor, job satisfaction, social support, and turnover intention}

Turnover intention showed a positive correlation with emotional labor $(\mathrm{r}=0.282)$, and a negative correlation with job satisfaction $(\mathrm{r}=-0.704)$ and social support $(\mathrm{r}=-0.362)$. This suggests that the higher the emotional labor, the lower the job satisfaction and social support, and the higher the turnover intention (Table 4).

\section{Factors contributing to the subjects' turnover intention}

To examine the factors contributing to turnover intention, this study performed a multiple regression analysis stage by stage. Model 1 explained $4.5 \%$ of the turnover intention, and the frequency of overtime work among the 5 variables had a significant effect on turnover intention $(\mathrm{p}<0.05)$. Model 2, which included emotional labor, explained $13.6 \%$ of the turnover intention, while monthly income, frequency of overtime work, and emotional labor had a significant effect $(p<0.05)$. Model 3 , which included job satisfaction, explained $49.9 \%$ of the turnover intention, while the frequency of overtime work 
and job satisfaction had a significant effect $(\mathrm{p}<0.001)$. Finally, Model 4, which included social support, explained $49.9 \%$ of the turnover intention, and the frequency of overtime work and job satisfaction had a significant effect like Model 3 ( $\mathrm{p}<0.05)$. Statistical power was higher in the order of job satisfaction $(\beta=-0.651)$ and the frequency of overtime work $(\beta=0.108)$.

Hence, it is demonstrated that the factors contributing to turnover intention were frequency of overtime work and job satisfaction: the higher the frequency of overtime work, the higher the turnover intention; the higher the job satisfaction, the lower the turnover intention (Table 5).

\section{Discussion}

Competition between dental care institutions is becoming so fierce due to advances in dentistry and the growing demand for dental care that they are moving towards a patient-centered business model. Owing to these changes, the professional role of dental hygienists is becoming increasingly important, and thus it is necessary to pay attention to turnover, which could lower dental care productivity and work as an obstacle to utilizing dental hygienists. In this context, this study identified the level of emotional labor, job satisfaction, and social support experienced by dental hygienists, and examined the factors that contributed to their turnover intention.

Dental hygienists' emotional labor scored 2.49 out of 4 points in this study, which was slightly higher than the median and similar to 2.74 in Yoon and Kim's results ${ }^{5)}$. This seems to show that patients were highly likely to perceive dental care as a paid service as many dental care services are not covered by insurance, and dental hygienists' emotional labor increased due to communication with physically and mentally sensitive patients ${ }^{29)}$. Accordingly, business leaders in dental hospitals or clinics need to understand dental hygienists' emotional labor and make efforts to establish a proper measure to reduce their emotional labor.

Meanwhile, their job satisfaction scores were 3.14 out of 5 , which was somewhat higher than the median. In terms of specific questions, the subjects were most satisfied with the sense of accomplishment or job stability

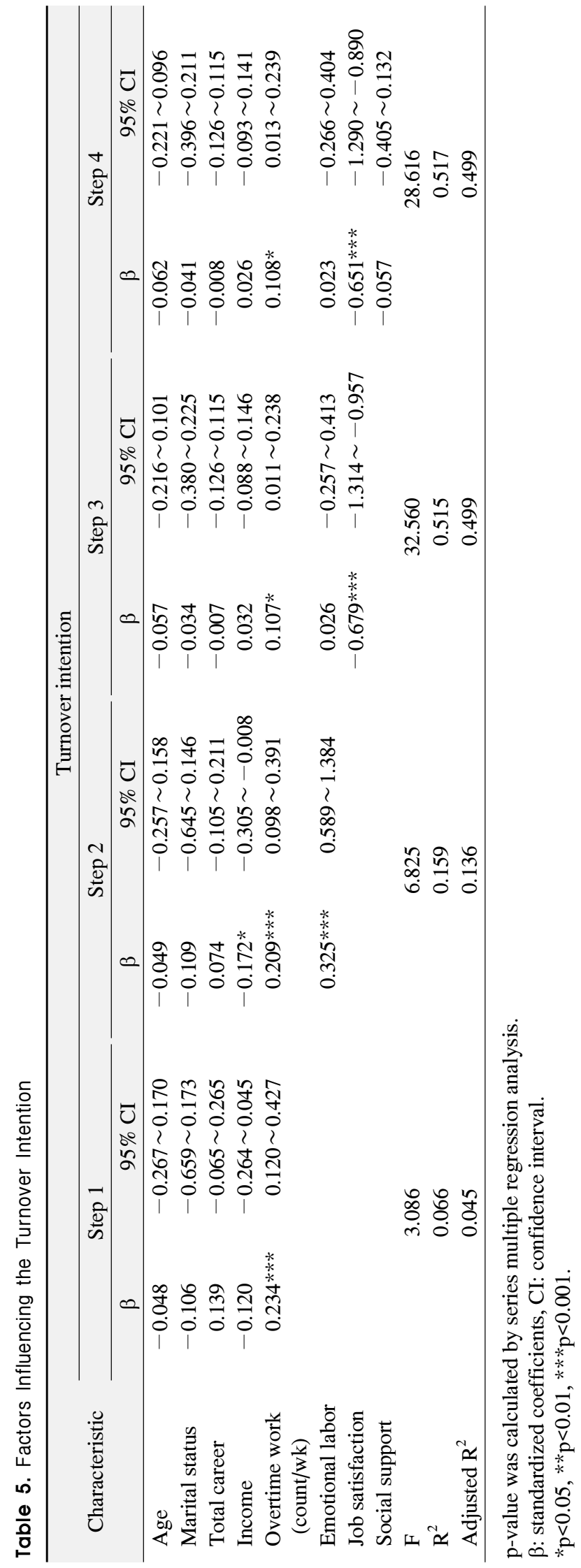


while they showed a low score in wage level compared to the amount of work they did. Hong et al. ${ }^{30}$ found that dental hygienists' job satisfaction was higher in the order of job prospects, independence, work environment, required workload, and compensation, while their wage satisfaction was lowest; Jang and Lee ${ }^{31)}$ also showed that they were most satisfied with occupational pride while they were least satisfied with compensation. Given these results that dental hygienists feel professional achievement, occupational pride, and job stability but do not think the compensation is adequate, it is necessary to pay more attention to how to improve dental hygienists' compensation to improve their job satisfaction.

Social support scored 3.04 out of 4 points, which was quite high. This result was similar to the 3.43 out of 5 points in Ko et al.'s study ${ }^{29)}$. It was reported that the higher the social support, the higher the job satisfaction ${ }^{15)}$, while the more positively an individual perceived the relationship with his or her boss, the lower the turnover intention since he or she was more stable emotionally ${ }^{7,32)}$. This is why hospitals need to pay attention to formal or informal interpersonal relationships, and team gatherings or mentorship would be some of the ways to develop a positive relationship between colleagues.

Dental hygienists' turnover intention scored 3.07 out of 5 points, which was higher than Jeung's $2.20^{25)}$ and similar to Lee et al.'s $2.79^{20)}$. Dental hygienists' higher score in turnover intention is not only affected by various factors including the work environment, a lack of sense of job accomplishment, marriage, pregnancy, and colleagues, but it is because most dental hygienists move on to another workplace to obtain a raise or promotion in proportion to their years of experience ${ }^{33)}$. Accordingly, dental care institutions need to establish a workplace culture or environment to reduce turnover intention and explore a way to provide proper compensation and employee benefits in proportion to dental hygienists' years of clinical practice.

An analysis of the factors that contributed to turnover intention found that the higher the frequency of overtime work, the higher the turnover intention, while the higher the job satisfaction, the lower the turnover intention. This finding was consistent with that of Yang's study on medical technicians ${ }^{34)}$ and Yoon et al.'s study ${ }^{12)}$ on dental hygienists. Accordingly, medical institutions need to explore a way to increase dental hygienists' job satisfaction and compensate them appropriately for overtime work to reduce their turnover intention, and to improve the dental work environment.

This study has the following limitations: Since it examined only dental hygienists in Seoul and Gyeonggi-do, it is difficult to generalize the results. In addition, since it did not consider other variables than the independent ones determined only by the questionnaire survey, we cannot entirely exclude the possibility that turnover intention might have changed due to other exogenous variables. Therefore, this study suggests that a multi-faceted study needs to be conducted by including a questionnaire and in-depth surveys that consider various exogenous variables related to turnover intention.

Despite these limitations, this study holds significance as it examined turnover intention considering emotional labor, job satisfaction, and social support.

\section{References}

1. Oh JS: A study on oral health service. Soc Sci Rev 21: 207-223, 2000.

2. Jeong EY, Kim MR: Relationship between job-stress and temporomandibular joint disorder in dental hygienists. J Korean Soc Dent Hyg 14: 381-390, 2014. https://doi.org/10.13065/jksdh.2014.14.03.381

3. Jeong KY, Han OS: A study on emotional labor, emotional burnout, turnover intention of dental hygienist. J Dent Hyg Sci 15: 280-286, 2015. https://doi.org/10.17135/jdhs.2015.15.3.280

4. Korea Employment Information Service: Magazine of employment trend. Retrieved October 20, 2017, from http://www.keis.or.kr/main/index.do(2015, November 2).

5. Yoon SU, Kim JS: Relations between emotional labor and job stress among some dental hygienists. J Korean Soc Dent Hyg 11: 179-188, 2011.

6. Choi MS, Ji DH: The comparative study on changes in job satisfaction and turnover intention according to the convergence mediating factors and the level of emotional labor in dental hygienists. J Korea Converg Soc 6: 27-34, 
2015. https://doi.org/10.15207/JKCS.2015.6.6.027

7. Jeong SB, Choi EM, Choi JS: The effects of emotional labor on burnout, turnover intention, and job satisfaction among clinical dental hygienists. J Korean Acad Oral Health 38: 50-58, 2014. https://doi.org/10.11149/jkaoh.2014.38.1.50

8. Bae SM, Kim HK: A status of determinant of the intention to turnover for dental hygienists. J Korea Acad Ind Soc 13: 59865992, 2012. https://doi.org/10.5762/KAIS.2012.13.12.5986

9. Ju OJ, Kim KS, Lee HO: Analysis of the correlation of job satisfaction to turnover among dental hygienists in the region of J. J Dent Hyg Sci 7: 251-256, 2007.

10. Jeong BJ, Kim HS, Hwang SK, et al.: A study on the according to the nursing shortage of job satisfaction and turnover intention of nurses. Korean J Health Serv Manag 5: 15-29, 2011. https://doi.org/10.12811/kshsm.2011.5.1.015

11. Kim HY, Choi JO, Seong MG: The effect of self-efficacy and job satisfaction of dental hygienists' on the organizational commitment and turnover intention. J Korean Soc Dent Hyg 12: 213-223, 2012. https://doi.org/10.13065/jksdh.2012.12.1.213

12. Yoon MS, Lee KH, Choi MS: A study on the turnover intention and job satisfaction of dental hygienists. J Dent Hyg Sci 6: 147-152, 2006.

13. Park JW: A study to development a scale of social support. J Nurs Sci 9: 22-31, 1986.

14. Kim JH, Lee YM, Joung HY, et al.: Effects of emotional labor, emotional intelligence and social support on job stress in clinical nurses. J Korean Acad Fundam Nurs 20: 157-167, 2013. https://doi.org/10.7739/jkafn.2013.20.2.157

15. Han HY, Lee JY, Jang IS: The moderating effects of social support between emotional labor and job satisfaction in clinical nurses. Korean J Occup Health Nurs 24: 331-339, 2015. https://doi.org/10.5807/kjohn.2015.24.4.331

16. Han SY, Cho YC: Covariance structure analysis on the impact of job stress, fatigue symptoms and job satisfaction on turnover intention among dental hygienists. J Korea Acad-Ind Coop Soc 17: 629-640, 2016. https://doi.org/10.5762/KAIS.2016.17.7.629

17. Heo SE, Ji JH: The mediating effects of burnout on the relationships between job stress and turnover intention for dental hygienists. Korean Public Health Res 36: 35-55, 2010.

18. Park YN, Choi YK, Ryu DY: Influence of organizational communication satisfaction on job satisfaction, organizational commitment, and turnover intention: focused on the mediated effects of interpersonal stress. Korean Soc Dent Hyg 15: 797-804, 2015.

https://doi.org/10.13065/jksdh.2015.15.05.797

19. Choi HN, Lim SR, Cho YS: Factors associated with turnover intention of dental hygienist. J Korean Soc Dent Hyg 10: 973-981, 2010.

20. Lee CS, Lim SH, Han JH: The effect of the intramural marketing activities in dental hygienist' on job satisfaction and turnover intention in dental hygienist. J Dent Hyg Sci 12: 15-22, 2012.

21. Kim KY: A study on the impact of psychological empowerment on job attitudes and turnover intention of dental hygienists. Korean J Soc Health Serv Manag 4: 1-10, 2010.

22. Lee JH, Choi JM, Lee YA: The help of experienced dental hygienists turnover verbal abuse and emotional reaction, and the resulting relationship. J Dent Hyg Sci 14: 563-570, 2014. https://doi.org/10.17135/jdhs.2014.14.4.563

23. Lee JW, Kim MK: The effects of personality types on turnover intention and job retention. J Korean Dent Assoc 48: 738-753, 2010.

24. Chang SJ, Gang HT, Kim SY, et al.: Research report--a study on the application of emotional labor or workplace violence (2013). Retrieved November 2, 2017, from http://oshri. kosha.or.kr/bridge?menuId=901.pdf(2014).

25. Jeung DY: Effects of emotional labor, educational training and psychosocial characteristics on job involvement in dental hygienists. Unpublished master's thesis, Yonsei University, Wonju, 2014.

26. Rye JN: Job stress and job satisfaction of dental hygienist as a middle manager of dental hospital clinic. Unpublished master's thesis, Kyungpook National University, Daegu, 2013.

27. Slavitt DB, Stamps PL, Piedmont EB, Hasse AM: Nurses' satisfaction with their work situation. Nurs Res 27: 114-120, 1978. https://doi.org/10.1097/00006199-197803000-00018

28. Yoon GS, Kim SY: Influences of job stress and burnout on turnover intention of nurses. J Korean Acad Nurs Admin 16: 507-516, 2010.

29. Ko MK, Kim MH, Lim DS, Ahn YS: The emotional labor and job satisfaction of clinical dental hygienists, in some area of Korea. J Korean Acad Dent Hyg 18: 1-14, 2016.

30. Hong SS, Jeong SH, Kim HY, Choi YH, Song KB: Comparison of job satisfaction between dental hygienist and 
assistant nurses in Daegu, Korea. J Korean Acad Oral Health 29: 172-183, 2005.

31. Jang GW, Lee GR: A study on the job satisfaction of the dental hygienists. J Dent Hyg Sci 6: 35-39, 2006.

32. Kim YH, Choi JH, Kim KE: The impact of job overload, relationship with senior on nurses' intention to quit their jobs: mediating role of emotional exhaust. J Korean Acad Nurs Adm 15: 372-381, 2009.
33. An SY, Kim HS: The effect of family, job, and organization-related situation to turnover intension of women managers. Women Stud 77: 5-48, 2009.

34. Yang JH: The relations of stress, job satisfaction, organizational commitment and turnover intention in medical technicians. J Digit Converg 14: 233-241, 2016.

https://doi.org/10.14400/JDC.2016.14.7.233 